\title{
How will NHI affect my practice? Workshop seeks answers
}

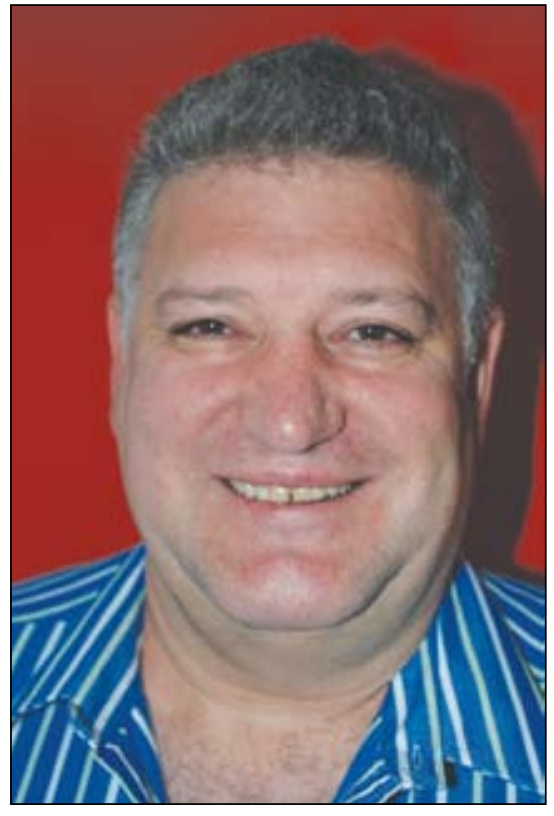

Len Deacon, independent health care funding consultant.

Picture: Chris Bateman

To capitalise on the impending national health insurance (NHI) system, private doctors need to change their mindsets from fee-for-service to capitation, sharpen up business models, practise preventive medicine in groups and outsource some office functions.

No matter what the final NHI model looks like, they will 'remain in the game', provided they're willing to change from a 'lone-ranger' culture to partnerships where cost analyses and clinical excellence keep both patients in their client drainage area and their bank balances healthy.

These were the key messages from an eclectic mix of relevant professionals who made presentations

Deacon said capitation
meant an abundance
mentality 'where the more
I keep my people healthy
and well, the more people
I'll be able to see', whereas
fee-for-service encouraged a
scarcity mentality where a
patient was more likely to
be 'leveraged'.

at a private sector workshop touring the Cape Peninsula last month aimed at equipping future $\mathrm{NHI}$-accredited doctors with appropriate knowledge. Entitled 'The business of medicine in preparation for the $\mathrm{NHI}^{\prime}$, and put together by CPC/Qualicare, Novartis and Sanlam, the presenters included a top labour lawyer, two management consultants, a human resources management trainer and an accountant.

Len Deacon, former principal officer of Anglo American's medical scheme/ turned independent consultant, referring to the impending sea-change, quoted Einstein to illustrate the impasse in equitable health care delivery and the adaptation needed. 'You cannot solve the problems we have today with the mindset that existed when they were created.'

\section{Mind shift plus action needed}

Deacon said capitation meant an abundance mentality 'where the more I keep my people healthy and well, the more people I'll be able to see', whereas fee-for-service encouraged a scarcity mentality where a patient was more likely to be 'leveraged'. 'If I can keep you out of my rooms and well by means of preventive, not curative medicine, I can see more people in my net of capitation and thus increase my income,' he explained.

The quality assurance required for provider accreditation would mean that the doctor whose 'downstream costs' (i.e. more tests for the same patient profile) were higher than his geographically closest competitor would lose out on the NHI contract.

(A certain number of private doctors will be accredited to the NHI in each district health area but this will depend on their practice profile and service appropriateness to each area's specific health needs.)

Labour lawyer Gerhardt van der Merwe (MacRoberts) said a snap survey of lawyer colleagues revealed a consensus that NHI-contracted doctors would have more patients, less time and need more staff. To create efficiencies, this would require the outsourcing of administrative and support functions through provider agreements.

Bigger practices were 'inevitable', making job descriptions for support staff and doctors and terms and conditions of employment, regular performance assessments and incentives and proper termination procedures vital. To illustrate, he said the Council for Conciliation, Mediation and Arbitration (CCMA) last year handled 200000 cases of unfair dismissal.

'If you don't have time, delegate human resource functions to a responsible employee - you don't have to run a sweat shop; just monitor people and deal with sub-optimal performance,' he advised.

While the NHI as originally
envisaged was 'clearly
unaffordable', elements of
it would nevertheless be
phased in over the next 5
years, probably bringing
to an end the current
modus operandi of the solo
practitioner.

Accountant Narisha Ishwarlall of Mazars said that to keep their businesses viable and sustainable, doctors needed disciplined separation of personal and business accounts, monthly bank reconciliations and regular debtor-age analyses. A fixed assets and equipment register would enable full tax write-offs annually for items under R7 000 and proper depreciation entries in the general ledger for the more pricey items. Monthly stock inventories at purchase price and, most importantly, an annual budget would enable proper cost and spending controls. 'Turnover is vanity, profit is sanity, but cash flow is reality,' she added. 


\section{Current system 'primitive, unsustainable'}

Workshop organiser, Dr Tony Behrman, CEO of the Independent Practitioners Association (IPA), CPC/Qualicare, said that while the $\mathrm{NHI}$ as originally envisaged was 'clearly unaffordable', elements of it would nevertheless be phased in over the next 5 years, probably bringing to an end the current modus operandi of the solo practitioner.

Afraid of disruption to
the status quo, the private
sector however suffered from
the 'prisoner's dilemma
where everybody does
what's best for them and
everybody is worse off,'
with constant tension
between the government,
regulators and service
providers.

'While the big bang has been replaced with more pragmatic voices the NHI is still going to be very expensive and off a small tax base. Perhaps it was all meant to make us sit up and see that the current situation is unfair and get us come to the party,' he added. The argument was no longer whether to have an NHI but how much could be afforded and what constituted prescribed minimum benefits.

To succeed doctors would need to bring different GPs and specialties together into local groupings. He believed many GPs were willing to help the government in running their outpatient departments and day hospitals and to work in public/private partnerships. 'All we ask is that you give us a fair wage, because up till now the hourly remuneration for an outpatient department session has been a bit of a joke,' he added.

Doctors had done well out of fee-forservice, even with late or non-payments, particularly at first when no limits were placed on medical benefits, and their systems supported it.

Afraid of disruption to the status quo, the private sector however suffered from the 'prisoner's dilemma where everybody does what's best for them and everybody is worse off,' with constant tension between the government, regulators and service providers.

Under the NHI, understanding the profile of their patients and forming partnerships to handle the risk profile while gearing up management and computer systems for capitation would bring doctors in line with the more successful multi-partner practices world-wide. 'Successful practices in capitation systems internationally are multi-practices - about three times more successful per capita partner than fee-for-service practices,' he stressed. Behrman said the current South African health care delivery model was 'primitive and unsustainable'.

\section{Change inevitable}

Deacon illustrated this by adding that over the past decade private hospital costs had increased by $121 \%$ and specialists costs by $120 \%$. Non-health care expenditure by medical schemes (e.g. broker fees) were 'exorbitant' and despite medicine pricing regulations having reduced the pharmaceutical product spend by $24 \%$ in real per beneficiary terms, contribution rates per medical scheme beneficiary had doubled over a 7-year period.

In 1996 there were 236 medical schemes compared with the current 117 - and he predicted that within 5 years there would be 'a mix of about 40' left. 'We cannot survive the way we're going at the moment; there has to be an interface with national health,' he added.

On the State side, funding had declined in real terms, understaffing was reaching crisis proportions and, while access had increased, the standard of care had deteriorated rapidly from 20 years ago when State tertiary care was easily the best in the country. 'We're faced with a heavier burden of disease, shortage of human resources, poor overall management, inadequate funding and a deteriorating infrastructure.' In the medium term, recapitalising State assets and improving hospital management would be vital to whether the NHI rescued South Africa from its current impasse or not.

To illustrate the gross inequities, Deacon quoted from the 2007/2008 national budget, adding that 'nowhere in the world will you find a country where $8.5 \%$ of the gross domestic product is spent on health, with $5 \%$ catering for 7 million people in private health care and the remaining 3.5\% catering for 41 million people in state health'.

He reminded doctors that South Africa was ranked 175th of 191 countries in the World Health Organization's overall health system performance. The most likely future landscape would be a single payer model allowing supplemental/topup health insurance with a further consolidation of medical aid schemes and private health care members paying more. Behrman said some rough arithmetic showed that under a capitation model, well-organised GPs stood to turn over R1.5 million per annum versus the R750 000 some wellpositioned GPs currently turned over (gross).

\section{Rough arithmetic showed that under a capitation model, well-organised GPs stood to turn over R1.5 million per annum versus the R750 000 some well- positioned GPs currently turned over (gross).}

Medical aid rates currently worked on roughly 3.5 fee-for-service consults per patient per annum (at R228, VAT included per consult, coming to R798 annually). Under capitation, dividing this by 12 gave a monthly capped rate of R66.50 per patient per month.

If the NHI allocated a practitioner 2000 patients per annum (numbers based on the old TransMed capitation model) this came to R130 000 per practitioner, paid up-front monthly in advance, totalling R1.560 million per annum.

Astute and ethical business people would benefit the most because all practice expenses had first to be deducted from the amounts cited. Behrman emphasised that his observations were 'preliminary' and did not cover scenarios such as chronic diseases, HIV and peer review of practice behaviour.

\section{Chris Bateman}

